\title{
Analysis on the supporting technology of the gob-side entry retaining
}

\author{
SHI Jian-jun \\ Institute of Geotechnical Engineering \\ China University of Mining and Technology(Beijing) \\ Beijing,China \\ shjjwrh@126.com
}

\author{
Safety Engineering College \\ North China Institute of Science and Technology \\ Beijing-east Yanjiao, China
}

\begin{abstract}
The research established a mechanical model which could reflect the basic features of rock stratum and made a profound investigation on the form and conditions of the fractures on main roofs. Based on mechanical analysis, the fracture location is difference when lane offshoot care is difference, cutting possibly the immediate roof even the main roof through superpower roof cutting, which can reduce the influence of roadway. The engineering detection and data analysis showed that a stable structure could be formed by the application of appropriate bolts (anchors) when the retained roadway is under the influences of the mining. In this manner, enough resisting forces will be provided to cut the roof. Then actual observation of fracture lines on the mined-out side demonstrates that the combination support is effective to form rational overhang length of the roof.
\end{abstract}

Keywords- the gob-side entry retaining; fracture location; combination support; superpower roof cutting; anchor bolt

\section{INTRODUCTION}

As a significant technique in roadway protecting in no pillar coal mining, the gob-side entry retaining could help to improve the recovery ratio of coal, to exploit coal resources rationally, to extend the lifespan for service of a mine, to reduce the problem of succession of exploitation, to reduce the amount of heading, to prevent combustion, to shorten the time of moving from two faces, and to avoid isolated-face. It's beneficial to both enhancing economic returns from technology and assuring safety in production. As a result, the technique of gob-side entry retaining is becoming an important research direction in underground coal exploitation. The deformation damage on main roof in a retained gob-side entry is manifested by the deformation and severe subsidence of the roadway. The reason for this is that the overburden strata gyrate axis-wise towards the mined-out side. In order to suit the deformation character of the main roof, the lane offshoot care we applied should be characterized by great supporting strength at an early stage, quickly growing resistance force, and appropriate supporting pressure; what's more, we need reducible quantity to adapt to the deformation. Along with the support inside the roadway, these two measures we applied could take good care of the immediate roof beyond a roadway, prevent it from dissociate with the covering main roof, assure its entirety, and cut-out both immediate and main roof on the mined-out side.
The deformation and failure of the roof of gob-side entry retaining is caused by the overburden strata rotating in the direction of gob with an axis, which leads to the severe subsidence. When the positions of fractures on main roof are different, the ways to protect the roadway are different. As a result, study on the fracture location above roadway is benefit for protecting roadway. [1-3].

The differences in fractures location on main roof in a retained gob-side entry cause significant diversities in the sizes of their compression and deformation as well as bad effects on the stability of surrounding rock around them. The deeper the fracture is in the rib, the harder the gob-side entry retaining will be.

So a research on fracture location on main roof beyond a retained gob-side entry, on how to control its position and transfer it into a favorable one will be of practical significance in the rational and economical maintenances of roadways.

\section{ESTABLISHMENT OF MECHANICAL MODEL}

We can use isotropic linear elastic constitutive relation to analysis, ignoring the effect of the main floor's thickness and the dip angle of rock stratum on the fractures location on main roof.

When developing joints exists in the main roof, it will have a great effect on the roof fracture. According to the experience of the scene, the main roof fractures firstly in the place where joints develop. The following analysis is the result of ignoring the effect of the joints[4].

We suppose that the main roof bear the uniformly distributed load and the load size can be obtained by the formula which academician QIAN Ming-gao give [5-7].

\section{MAIN ROOF OF ROADWAY IN LATERAL FRACTURE}

\section{A. Ignoring the effect of immediate roof}

Model simplified mechanical model is stress as shown in Fig .1.

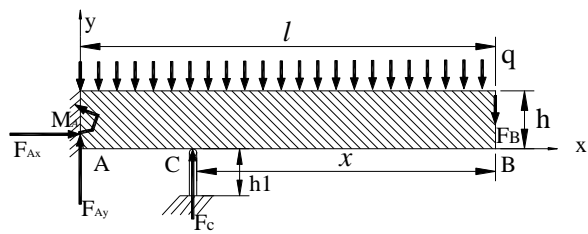

Figure 1. The force of main roof beam

In figure $\mathrm{F}_{\mathrm{Ax}}-$ coal rib end horizon binding; 
$\mathrm{F}_{\mathrm{Ay}}$ - coal rib end vertical binding;

$\mathrm{M}_{\mathrm{A}}$ - plane bending moment binding

$\mathrm{F}_{\mathrm{C}}$ - cut the roof resistance

$\mathrm{F}_{\mathrm{B}}$ - the shear force between rock

$q$-overburden strata applied load

According to the model, we can establish a balance equation :

$\sum F x=0:$

$$
F_{A x}=0
$$

$\sum \mathrm{Fy}=0$ :

$$
q l=F_{A y}+F_{C}-F_{B}
$$

$\sum \mathrm{M}=0$ :

$$
M_{A}+F_{C}(l-x)=\frac{1}{2} q l^{2}+F_{B} l
$$

The torque analysis of main roof beam as shown in Fig .2.

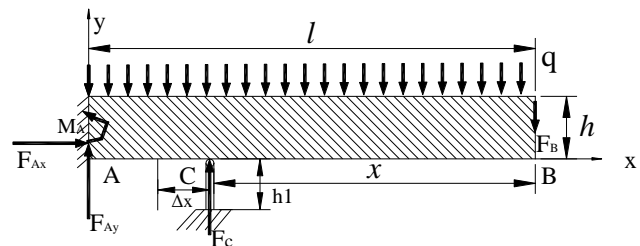

Figure 2. The torque of main roof beam

The torque of AC externally.

$$
\frac{1}{2} q(x-\Delta x)^{2}+F_{B}(x-\Delta x)
$$

The torque of AC internally.

$$
\frac{1}{2} q(x+\Delta x)^{2}+F_{B}(x+\Delta x)-F_{C} \Delta x
$$

It can be inferred when the force on the overburden strata are the uniformly distributed load and the immediate roof out of the roadway turned down without touching the whole main roof or the coal caving reduces the supporting of the main roof and the supporting (or the pillar) beside the gob side roadway deformation do not provide much torque, the main roof fractures in the positions of the supporting besides the outer roadway[8].

\section{B. Considering the influence of the immediate roof}

By the model, we can continue to assume that considering the effect of immediate roof. If roadway roof by lane side support content (or pillar) and the immediate roof support, and its deformation is not big, can be regarded as rigid body, then the model is simplified directly to a cantilever beam, as shown in Fig .3.

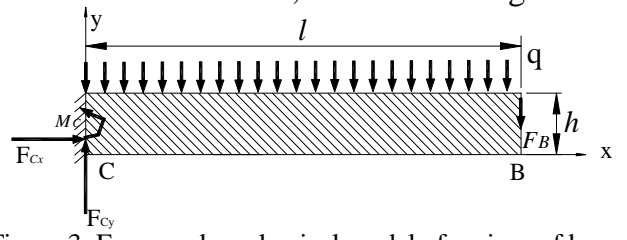

Figure 3. Force and mechanical model of main roof beam

In figure: $\mathrm{F}_{\mathrm{Cx}}-$ coal rib end horizon binding;

$\mathrm{F}_{\mathrm{Cy}}-$ coal rib end vertical binding upon both

parties;

$\mathrm{M}_{\mathrm{C}}-$ Plane torque binding upon both

parties ;

by $\sum \mathrm{M}=0$

$$
M_{C}=\frac{1}{2} q l^{2}+F_{B} l
$$

The cases are the same as above a condition, the main roof is in roadway lateral fracture.

When the immediate roof collapse gangue behind it'll be completely up to the top of the roadway roof support is good. In this case, the catch point $\mathrm{C}$ move to mined-out area as shown in Fig .3, therefore gangue accumulation, the formation of overlying rock supporting role, main roof of roadway in the far lateral fracture.

\section{MAIN ROOF OF ROADWAY IN MEDIAL FRACTURE}

Continue to assume that the support of gob side is not enough to provide great support of cases:

$$
F_{C}<<q l+F_{B}
$$

So, cut the roof failure, therefore, this condition is equivalent to a cantilever beam model, according to the above analysis the biggest failure torque for:

$$
M_{A}=\frac{1}{2} q l^{2}+F_{B} l
$$

The most unsafe section appeared in roadway in coal rib, at this time main roof of roadway in coal rib side fracture[9-11].

So the superpower roof cutting measure, can be in roadway lateral cutting roof and can guarantee roadway roof stability, thus cutting roof resistance must satisfy:

$$
F_{C} \geq q l+F_{B}
$$

\section{SURROUNDING ROCK CONTROLLING TECHNOLOGY}

If the rational use of superpower cutting roof support on one hand to avoid in the lane basic support serious deformation and failure, on the other hand can be gob side cut the roof.

\section{A. Cut the roof in gob side}

Forced to cut the top bracket structure is composed of a set of roadway in gob side edge along the roadway, the direction of the development of steel and the adjacent single hydraulic prop composition. The specific settings is: type steel beam and monomer its top through the cross roof beam connected component cutting roof support, but also in the direction of roadway to cut the top line connection composition, bottom by the special iron shoes together, in order to avoid too much pressure, and support than to increase friction resistance, balance goaf take down the waste produce side pressure.

\section{B. The roadway reinforcement}

The gob-side entry roadway retained in the original design of roadway support on the basis of the patch (anchor beam strengthening support measures, to ensure that face after mining roadway roof is complete, ensure to form stable cantilever beam structure, separation rock hanging in a hard main roof above.

\section{Roadway reinforcement of the ribs}

Reinforcement design is that the coal rib use anchor cable additional, in gob side and roof use bolt where complement to reinforce the gratitude are strengthened. Strengthening in the coal from the roof for $1.2 \mathrm{~m}$ section of 
a row of anchor cable beam, the Angle of tilt to the roof above $15^{\circ}$, span $1.5 \mathrm{~m}$; And set and gob rib steel support back not less than three root half logs, half log specification is $\phi$ and $\mathrm{cm}$ long, $1.4 \mathrm{~m}$; Roof near the gob side fill play two row of roof bolt, including a row of clingy corner steel bracket above and to the gob tilt $15^{\circ}$, another row spacing this row bias coal rib direction and $\mathrm{cm}$ place, vertical to the anchorage; Bolt spacing sixty $\mathrm{cm}$, specifications for $\varphi 22 \times 2200 \mathrm{~mm}$ of deformed steel bar bolt.

\section{EXPERIMENTAL RESEARCH ON ENGINEERING}

\section{A. Production technology condition}

The working surface 1528 in GeQuan Coal Mine is monoclinal structure, its immediate roof is argillaceous siltstone, and the main is Fine sandstone. The roof is Moderate stability roof; the immediate is the three types of roof.

\section{B. The support design of the gob-side entry retaining}

The pre reinforcement of roadway, primary support, secondary support are the construct technology of the gobside entry retaining.

\section{1) The pre reinforcement}

The pre reinforcement procedure of the transportation roadway in workface 1528: fixed double-deck metal mesh block gangue the rib of workface $0.4 \mathrm{~m}$ distance, make roof and rib anchor bolt, the reinforcement distance in advance is $70 \mathrm{~m}$, when closing to workface complement two rows of anchor bolt reinforcement of immediate roof. Use anchor bolt to control coal rib deformation.

\section{2) The primary support}

Primary support involves most of the left lane construction procedure. General: mining face frame before hanging nets, push the scraper shift frame, a set cutting roof support (guard help monomer and $\pi$ type steel beam), set up two rows monomer strengthen support.

\section{3) The secondary support}

Secondary support involve: remove coal rib and intermediate each a row of monomer and overhaul roadway. When the roadway dynamic pressure stable deformation or $2 \sim 4 \mathrm{~mm} / \mathrm{d}$, remove solid coal rib a row of monomer, When the mining roadway pressure when the basic disappear or deformation $0 \sim 2 \mathrm{~mm} / \mathrm{d}$, but the decrease of the intermediate monomer a row, When the roadway deformation stability of top and bottom after deformation $0 \sim 2 \mathrm{~mm} / \mathrm{d}$, roadway undercover trimming later can be achieved by using requirements. Anchor cable installation rule is every other row to play two anchor cable, the anchor cable is the row spacing take for $1.5 \mathrm{~m}$. The initial supporting design of roadway is shown in Fig.4.

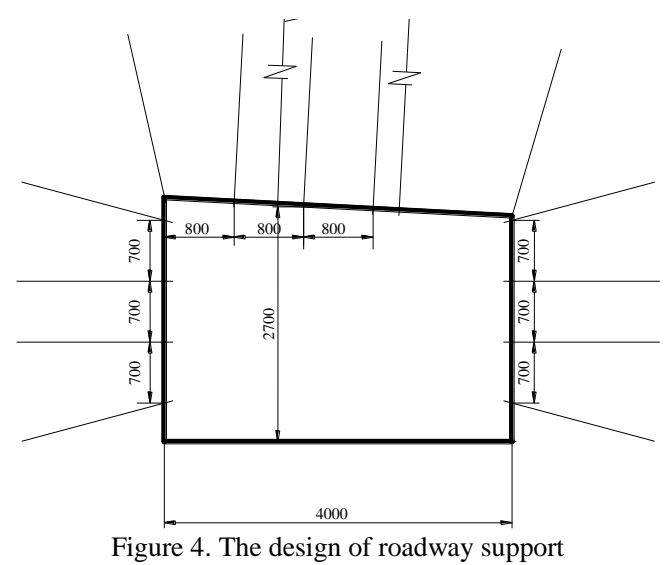

\section{The measured of the roadway}

1) Measuring point layout

In the mining advanced to transport lane for deformation observation. A total of five deformation observation point, in interconnection layout zero point number, here due to mining influence data difficult observation; The rest of the three point every $30 \mathrm{~m}$ along the direction of advance of the face are arrangement, the last point and 3 point are $29 \mathrm{~m}$ arrangement. Before the recovery of sensors are completed, face began to push for observation, when in gob stop observation; Observation take traditional cross stationing method, the main monitoring roadway roof and floor, and two rib relative nearer the quantity.

2) Observation results analysis

According to the no. 1 point observation results are all typical deformation data curve, mining working face before master station, mining face began to observed point into the gob stop after monitoring, can reflect the secondary mining activities under the influence of the roadway deformation process.

From the observation data, it is known that the roadway in the second the mining influence, has the following deformation features:

\section{a) Nearer the rule of the roof and floor}

By the observation that the analysis or closer to the bottom of the main were, roof convergence speed and less than the total displacement were bottom. The data can be description: roof subsidence accounted for about $35 \%$ of the total nearer, bottom amount were about $65 \%$ of the total nearer, as shown in Fig .7 shows. This means that the recovery process, the lane side support for left lane roadway pressure influence size.

b) Two ribs displacement with the mining face advance rule

Two ribs deformation the coal rib dishing occupied the main position, gob side dishing speed and total displacement were less than coal help.

Gob dishing accounted for about $39 \%$ of the total amount of nearer, coal rib dishing about of the total amount of closer to about 61\%. This is because the gob side to strengthen support and gob side waste compaction strength after than for large coal rib. 


\section{CONCLUSION}

When the fracture location is difference when lane offshoot care is difference. The superpower cutting roof measures can cut the roof in the roadway and guarantee roadway roof stability.

The measures, individual jacks compulsory cutting, active support by anchor cable, anchor net and individual jacks with hinge top-beam, could provide enough resisting forces. The application of mount half-round timber on $\pi$ pattern steel, metal net anchor with bolt replace roadside packing in mined-out area.

Using the superpower cutting roof combination support form, the actual observation of fracture lines on the minedout side demonstrates that the combination support is effective to form rational overhang length of the roof.

\section{ACKNOWLEDGMENT}

This work was financially supported by the Fundamental Research Funds for the Central Universities (3142013100); the National Natural Science Foundation(51044009); the Natural Science Foundation of Hebei Province (E2012508002).

\section{REFERENCES}

[1] Sun Henghu, Zhao Bingli. Theory and practice of gob. Beijing: China Coal Industry Publishing Press, 1993, pp.51-71.
[2] Xie Wenbing, Yin Shaoju, Shi Zhenfan. The key problem study about gob-side entry retaining in top-coal caving mining face. Journal of China Coal Society, 2004, 24(2) , pp.146-149.

[3] Zhang Guohua. Roof cracking reason analysis about gob-side entry retaining under initiative support. Journal of China Coal Society, 2005, 30 (4) , pp.429-432.

[4] Teng Yonghai, Yan Zhenbin. Study on law of overburden split developing in mining process. Journal of China Coal Society, 1999, 24(1) , pp. 25-28.

[5] Qian Minggao, Liu Tingcheng. Ground pressure and its control. Beijing: China Coal Industry Publishing House, 1984, pp. 62-67.

[6] Qian Minggao, Miao Xiexing, Xu Jialin, et al. Theory of key layer on strata control. Xuzhou: China University of Mining and Technology Press, 2003

[7] Qian Minggao, Miao Xiexing, He Fulian. Analysis of key block in the structure of voussoir beam in longwall mining .Journal of China Coal Society, 1994, 19(6) , pp.557-563.

[8] He Tingjun. The breaking place prediction of face end main roof flap top in the gob side entry retaining. Journal of China Coal Society, 2000, 25(1) , pp. 28-31

[9] Bai Jianbia , Zhou Huaqiang , HouChaojiong , et al. Development of support technology beside roadway in goaf side entry retaining for next sublevel. Journal of China University of Mining \& Technology, 2004, 33(2) , pp.183-186.

[10] Ma Liqiang, Zhang Dongsheng, Chen Tao. Study on packing body supporting resistance of enter-in packing for in-situ gob-side entry retaining in full-mechanized top-coal caving mining face. Chinese Journal of Rock Mechanics and Engineering, 2007, 26(3) , pp.544-550.

[11] Guo Yuguang, Bai Jianbiao, Hou Chaojiong. Study on the main parameters of side packing in the roadways maintained along gobedge. Journal of China University of Mining and Technology, 1992, 23(2), pp.1-11. 